\title{
FUENTES LEGISLATIVAS ANTECEDENTES DE LA POLÍTICA MONETARIA DE CARLOS III
}

\author{
Maria Dolors Mateu Ibars
}

La archivística ofrece en sus técnicas de clasificación documental interesantes compilaciones de documentos que revelan su naturaleza y categoría diplomática a la vez. Así, los llamados volúmenes de Cartas Acordadas, y concretamente los Índices que figuran en las series sistematizadas de los registros borbónicos de Audiencia Política (1714-1868), son característicos.

Constituyen una buena base heurística para estudiar, posteriormente, el documento in exienso. Entre los variados temas que contienen para la Historia Monetaria del siglo XVIII en el Principado de Cataluña, se ofrece una selección de documentos que permiten apreciar la evolución legislativa de los monarcas y su repercusión en la política y economía.

Poco recordada la variación monetaria que llevó a cabo Carlos III en 1772 , requiere previamente una cronología marco que justifique la trayectoria monetaria tanto en la historia de Hispania como en Indias.

Así, en 1733 Felipe V nombró a su hijo, el futuro Carlos III, generalísimo de su ejército de Italia, que reincorporaría Nápoles y Sicilia. Coronado en Palermo en 1734, apoyó a su hermano Felipe, que pretendía Parma y Plasencia, contra Austria e Inglaterra; en 1754 rehabilitó al marqués de la Ensenada, que había sido exonerado por Femando VI. El pacto de Familia se suscribió en 1761 por el que los cuatro Borbones, el de Francia, Luis XV (1715-1774), el de Nápoles-Sicilia, Fernando III (1759), el de Parma-Plasencia (1749-1796), y el mismo Carlos III, titulado Hispaniarum et Indiarum Rex, se garantizaban mutuamente.

En 1760 se cré́ la Contaduría general de Propios y Arbitrios. Posteriormente, en 1762 , se perdió La Habana, tomada por los ingleses, y luego Manila, ganada por los mismos. La colonia del Sacramento se ganó en 1762 y por el Tratado de París, firmado en 1763, Francia renunciaba a Nueva Escocia, Cabo Bretón e islas y costas de San Lorenzo; Inglaterra restituyo a España lo conquistado en Cuba y Filipinas pero Gran Bretaña obtuvo la Florida, y España devolvió a Portugal la colonia del Sacramento. 
En la Secretaría de Estado, el marqués de Grimaldi sustituyó a Ricardo Wall. En 1776 se organizó la administración indiana, creando el Virreinato de Buenos Aires, confirmándose el de Nueva Granada - que databa de 1739- y el de Perú. Se crearon ocho capitanías generales, independientes: Nuevo México, Guatemala, Chile, Caracas, Cuba, Puerto Rico, Santo Domingo, Luísiana y Ia Florida, que habían sído recuperadas en 1763. En 1779 comenzó la guerra con Inglaterra por razón de la emancipación de las colonias inglesas. En 1782 se recuperó Guernica, que había sido ocupada por ingleses en 1708, y se sitió Gibraltar. En 1783 se firmó la paz con Inglaterra, recuperada Menorca, pero no Gibraltar; en 1784 se bombarde6 Argel y en 1785 se firmó la paz con este país.

La reforma monetaria se llevó a cabo en 1772 . El sistema tenía por base en el oro: el escudo, con su mitad, y sus múltiplos, de 2 escudos o doblón; media onza o seis escudos; $y$ onza $u$ ocho escudos. En la plata: el real; o el medio real; el doble, que era el real de a dos; el medio duro o real de a cuatro; y el duro que venía a continuar la función del antiguo real de a ocho. En el cobre: el maravedi, o pieza ínfima; los dos maravedis; los cuatro y los ocho maravedís, con los que Carlos III venía a mantener el sistema de su padre, Felipe V y de su hermanastro Fernando VI. En 1750 se había publicado una ordenanza regulando que las monedas de oro y de plata labradas en las casas de México y otras de Indias, habían de ser: las de oro, de 22 quilates ( 917 milésimas); y las de plata, de 11 dineros (917 milésimas).

Carlos III se encontró con un sistema sencillo en tres metales, sin tener que resolver los problemas que plantearon a su padre Felipe V los antiguos reinos de Castilla-León, Aragón y su Corona y Navarra con su tradición monetal, para ajustarlos a lo establecido en 31 de octubre de 1716, cuando se ordenó que «la moneda llamada Provincial, es decir, acuñada en España, fuera de la ley y peso que se labró en 1707 y 1708 en Castilla. En 25 de abril de 1707 fue la batalla de Almansa cuyo resultado torció las pretensiones del Archiduque Carlos.

- Hasta 1754 las acuñaciones fueron de mejor ley que las posteriores, o sea, se mantuvo el fino de las de Fernando VI, que era entre 911 y 917 milésimas, en el oro. Desde 1764, después del tratado de París hasta 1772 , la ley fue de 900 , en onzas, medias onzas y doblones 8,6 y 2 escudos respectivamente; pero el escudo sencillo había bajado a 896. En 29 de abril de 1772 , desde Aranjuez mando y luego por pragmática de 3 de junio del mismo año, que se extinguiera toda la moneda de oro y plata y se labrara otra de nuevo cuño a expensas del Estado. Tanto en las Casas de Moneda de España como en las de América habían de llevar la leyenda Carolus ... Dei gratia Hispaniarum en Indiarum Rex abreviada, con su busto en anverso y sus 
armas en reverso, Auspice Deo in Utroque Felix con el Toisón con gráfila y cordoncillo agallonado y retorcido en plano.

- Se distinguía entonces en moneda provincial, que era la acuñada en España, y la de Indias. Las de cobre se labraban en la Casa de Moneda de Segovia, cuya marca, la puente, llevan. La extinción de la moneda antigua de vellón ordenada en 1772 se hizo a expensas de la Real Hacienda con un plazo de seis años para su recaudación y conversión en cobre de uno, dos y cuatro y ocho maravedís.

Hechos políticos notables como: la guerra de Marruecos; la expedición a Argel promovida por Grimaldi para atacar a los corsarios; la sublevación de Tupacamaru en 1776 en el Perú; la constitución de Sociedades de Amigos del País en 1775 en Madrid, Zaragoza, Granada y Santa Cruz de la Palma, sucesivamente, y Murcia y Sevilla, Córdoba, Oviedo, Segovia y Filipinas y otras ciudades, van marcando las pautas de comportamiento y desarrollo económico.

El Archivo de la Sociedad Económica de Amigos del País, en Madrid, contiene abundante documentación sobre el estado de diversas ciudades de Cataluña. También la documentación de la legación de España en Génova y Turín, remitida por la legación española en 1836, y que contiene la de la extinguida embajada en Génova, actualmente en el Archivo de la Corona de Aragón, es un arsenal minucioso de noticias epistolares que unen, al detalle espontáneo de la misiva, el acontecer de hechos notables, con soportes adyacentes de impresos, autógrafos, minutas y legislación de la época. Nuestra tarea aportó con A.M. Aragó unos inventarios analíticos que dan cuenta de ello, como la correspondencia cruzada entre el conde de Floridablanca y el marqués de Grimaldi.

Ordenado el sistema monetario en 1782, se crea el Banco de San Carlos, por Real Cédula a iniciativa de Francisco Cabarrús.

Carlos III abandonó el antiguo macuquino de la plata que mantuvieron su padre y hermano, propios de Indias, acreditando el columnario de las Casas de la Moneda de México y Potosí, Lima, Guatemala, Santa Fe de Bogotá y Santiago de Chile, Popayan y Nueva Guatemala que se mencionan en la reforma de la ley de 1772 .

Vista en síntesis la evolución cronológica de eventos políticos y su determinación en lo que a la política monetaria siguió Carlos III, se expone una relación cronológica de regestas documentales del mencionado volumen 23 bis, de Cartas Acordadas del Archivo de la Corona de Aragón, transcritas literalmente, con respeto de grafías y ortografías. Por la espontaneidad de redacción, el hipérbaton de la época y las cláusulas determinativas de la ejecución de las pragmáticas se aprecia su valor anatemático y axiomático que incidiría en su cumplimiento. 
Así se inicia: ${ }^{2}$ El Índice General de Reales Cédulas y Provisiones expedido por el Real Consejo y Cámara de Castilla. Cartas Acordadas de sus respectivas Secretarias dirigidas al Señor Gobernador General Señor Regente y Audiencia del Principado de Cataluña. Como también de las Cartas Ordenes escritas de Orden del Rey por sus respectivos Secretarios del Despacho Universal dirigidas a dichos governadores generales Regente y Audiencia. Como también de otros Tribunales y Ministros Superiores, Acordadas $i$ de la Real Audiencia. Al folio 1 contiene el Real Decreto de la nueva Planta de Govierno de esta Audiencia y Principado.»

Las disposiciones de Felipe $\mathrm{V}$ fueron las que permitieron que al Ilegar el reinado de Carlos III, su Hacienda tuviera un sistema monetario libre de las perturbaciones que ocasionó la variación de los antiguos reinos de la Corona de Aragón y la de Navarra y particularmente el año base fue el de 1718.

Dichas pragmáticas constituyen un cuerpo legislativo que arbitraría, con Cartas y Órdenes el quehacer monetario, con referencias a las monedas que incorporó más tarde Carlos III.

\section{RELACIÓN DOCUMENTAL TRANSCRITA LITERALMENTE}

1) 1716 , abril, 7 .

Real Pragmatica de 7 de abril en que se declara la pena en que incurren los fabricadores de moneda falsa con cuño, o estampa de otras coronas (fol. 21).

2) 1718 , junio, 16 .

Carta del Señor Don Joseph Rodrigo de fecha de 16 de junio 1718 en que se participa haver su Magestad resuelto que de ningun modo tengan curso los dinerillos falsos de Aragon sino que se vayan recogiendo en Cajas reales que se establezcan en aquel reyno y Principado, comprandolos a pesso por quenta de la Real Hacienda al precio de Cobre, o, segun el balor intrinseco, que tuviere el metal de que fuere (fol.111).

\section{3) 1718, junio, 16.}

Carta del señor Don Joseph Rodrigo de fecha 16 de junjo de 1718 sobre la baja ha mandado S.M. se execute en seis meses de los dinerillos de Aragón y que lo mismo se execute sobre los dinerillos fabricados en este Principado en tiempo del intruso govierno (fol. 112). 
4) 1718, junio, 16.

Carta del señor Don Joseph Rodrigo de 16 de junio de 1718 en que se manda al Marqués de Castel Rodrigo avise luego y sin dilación si la Casa de Moneda de la Ciudad de Barcelona es de Ingenio de agua y es capaz de labrarse en ella la moneda de vellon de quartos y ochavos de cobre (fol. 115).

5) 1718, junio, 17.

Carta del Señor Don Miguel Fernandez Duran en que dirige las antecedentes Cartas del Señor Don Joseph Rodrigo de Orden de Su Magestad y manda que los ensayos de Monedas de Metales, y todas las demas averiguaciones, y providencias que encarga Su Magestad se ha de tratar de liberar y concordar con asistencia de la Audiencia y del Intendente de este Principado dandosse diferentes reglas de lo que se devera executar en esta dependencia (fol. 116).

6) 1718 , junio, 24 .

Carta del Señor Don Joseph Rodrigo de 24 de junio, en que luego luego (sic) se haga el ensayo de los dinerillos buenos de Aragon, y de los de Cathaluña fabricados en tiempos del Intruso govierno y haviendolo hecho se declare la vaja que se ha de hazer en cada uno de los seis meses sin que preceda otra diligencia (fol. 121)

7) 1718, junio, 23.

Carta del Señor Don Joseph Rodrigo en que se acompaña la Real Provision del Consejo se manda, que por lo que mira a la vaja que se ha de hacer de los dinerillos de Aragon se hagan los ensayos y lo demas que convenga para la division de las seis partes correspondientes a la vaja de los seis meses y algunas providencias que se devian practicar antes de publicar la Provision del Consejo (fol. 122).

8) 1718, junio, 25

Real Provision del Concejo (sic) de fecha de 25 de junio con que se manda la remission y entrega de los dinerillos de Aragon, y diferentes providencias que se establecieron para recoger dicha moneda de vellon (fol. 122).

9) 1718 , julio, 30 .

Real Provision de Consejo de 30 de julio de 1718 para que no se puedan hacer luhiciones de censos, censales y treudos graciosos con las monedas y dinerillos de Cruz de Aragon, y los Cathalanes fabricados en el año 1653, y los del tiempo del intruso govierno (fol. 138). 
10) 1718 , octubre, 15 .

Carta de Don Joseph Bordanova Escribano de Camara y de govierno del Consejo en que de orden del Consejo passo a manos del Señor Marques de Castel Rodrigo copia authorizada de la Pragmatica, que se public 6 en Madrid para que se admita, y corra en el publico comercio la nueva moneda de vellon que en ella se expressa, para que se den las providencias, que conviniere darse, para su observancia (fol. 155-156).

\section{1) s.f.}

Carta Orden del Señor Regente dirigida a Don Salvador Prats y Matas de fecha (en blanco) en que incluye copia de la que le dirigio su Excelencia para que entregue por via de cambio al thesorero general los dineros tuviesse en su poder del derecho del sello en la moneda no sujeta a baxas, para pagar los Marineros foraneros que han tomado Plaza en el Navio del San Phelipe (fol. 156).

12) 1718 , noviembre, 27.

Carta del Señor Don Miguel Fernandez Duran de fecha de 27 de noviembre 1718 en que participa al señor Marques de Castel Rodrigo haver Su Magestad resuelto que por ahora y hasta nueva orden no se haga novedad en este Principado de abatir y prohibir del todo los dinerillos de Cruz, buenos de Aragón y los catalanes del intruso govierno, aunque llegue el termino de la ultima vaja (fol. 177).

\section{3) 1719 , enero, 3.}

Carta del Señor Don Joseph Rodrigo de 3 de enero 1719 en que participa haver Su Magestad resuelto se abate, reprueva y prohiba en Cataluña la Moneda de Vellon de dinerillos de Cruz de Aragon y su uso, y curso que huviere en las Arcas Reales, como está mandado y que por vando, como las otras providencias que en dicha Carta orden se expressan (fol. 178).

14) 1720 , abril, 6 .

Carta del Señor Don Joseph Rodrigo de 6 de abril de 1720 en que participa haver su Magestad resuelto que no se prohiba (en la Cerdaña no mas) el curso de la moneda francesa y otras providencias, que devan practicarse (fol. 34).

15) 1721, junio, 14.

Real Provision del Consejo de 14 de junio de 1721, en que se declara la forma en que debe correr la moneda francesa en la Cerdaña española (fol. 186). 
16) 1721 , julio, 30 .

Real Provision del Consejo en que se manda se restablezca en la ciudad de Manresa la tabla de los Comunes Depositos que havia antes (fol. 191).

17) 1722 , enero, 10.

Carta del Señor Abad de Vivanco de 10 de enero 1722 en que participa la real resolución de Su Magestad de haver concedido a las ciudades de Barcelona, Tarragona, Gerona, Lerida, Tortosa y Cervera, la gracia de voto en Cortes Generales (228).

18) 1724 , septiembre, 12 .

Real Cedula de 12 de Septiembre 1724 en que se participa la muerte del Señor Don Luis Primero, $y$ haver su Magestad resuelto bolver a gobernar la Monarquia, como a tal Rey Natural y propietario de ella (fol. 1).

19) 1726, enero, 14.

Copia autorizada del Real Decreto de 14 de enero 1726, con su publicación en que se expresa Su Magestad haver resuelto que el escudo de oro, que hasta ahora pasava por 16 reales de plata doble valga 18; el Doblon de a dos escudos 36; el de a quatro 72 , el de a ocho 144 y asi a proporcion lo que correspondiere en vellon, para el curso del Comercio sin que se exceda de la referida regla precaviendo las dudas que puedan ofrezerse en las obligaciones, escrituras, vales, y otros instrumentos, que se hayan de satisfacer en oro por ser la especie en que se permiti/ eron (fol. 64).

20) 1726 , febrero, 8 .

Copia Authorizada del Real Decreto de su Magestad de 8 de Febrero 1726 y de su publicacion en Madrid el dia 9 con el qual ha resuelto Su Magestad que el peso escudo de plata que hasta aqui ha pasado por ocho reales de plata Doble valga nuebe reales y medio de plata de la misma moneda, corriendo debajo de este prezio, todos los pesos y medios pesos, que vienen de los reynos de Indias; respecto de la moneda de Medios reales y dos reales de plata que oy corre, a excepcion de los nuebamente fabricados, es sumamente diminuto: Manda, que por el espacio de tres meses se reziba segun el valor que oy tiene por todos sus thesoreros, Arqueros, Depositarios y Arrendadores, sin hazerse novedad en la Moneda provincial de plata que tienen los Reynos de Aragón, Valencia y Cathaluña y que se de el Marco de Ley de onzas dineros, el que se corresponda segun el augmento, que se da a los pesos de Indias (fol. 66).

21) 1726 , febrero, 23.

Real Decreto de Su Magestad de 23 de Febrero 1726, y suplicacion de 25 , con copia concordada en que se declaran las dudas ofrezidas sobre el 
aumento dado a la moneda de oro, y plata, y como deve entenderse y condescenderse dicho augmento en una y otra parte (fol. 68).

22) 1726 , abril, 2 .

Copia authorizada del Real Decreto de Su Magestad de 2 de abril 1726 y su publicacion, 4 del mismo mes para que se recojan en el termino de tres meses los pesos fabricados en la Casa de la Moneda de la ciudad de Sevilla y en el interin, que corra por ocho reales de plata doble (fol. 79).

\section{3) 1726, mayo, 25.}

Real Provision de 25 de Mayo 1726 para que la Audiencia informando informes de los ensayadores, contrastes y demas ministros de la Casa de la Moneda, Informe de si el valor y peso de los Doblones en este Principado es mas fuerte que el de los Reinos de Castilla (fol. 83).

24) 1726 , marzo, 18.

Real Provision de 18 de marzo 1726 para el Ayuntamiento de esta Ciudad pueda dirigir sus representaciones assi de a las Real de su Magestad assi como a los señores del Consejo y sobre el Modo con que manda su Magestad se recoja la Moneda de medios Reales y dos reales de plata Doble, e, que se han de recojer y abatirse (fol. 69).

25) 1726 , octubre, 31 .

Real Provision de 31 de octubre 1726 en que se declara el valor y peso en que han de correr y admitirse los pesos y medios pesos y se manda que se reziva toda la moneda de plata antigua por el propio valor que tiene, hasta que su Magestad ordene lo que se huviere de executar (fol. 103).

26) 1728 , abril, 23.

Real Provision en que va inserto Real Decreto de Su Magestad en que manda, que los Medios reales, reales y piezas de a dos Reales que no tienen la figura redonda, no tengan curso sino basta ultimo de Julio proximo (fol. 163).

27) 1728 , noviembre, 8 .

Papel de su Excelencia de 8 de noviembre 1728 en que esta inserta la Real Resolucion de su Magestad para que se prevenga a todos los Corregidores se dediquen para aberiguar los agresores de una porcion de Moneda de Reales de plata y de a dos que se han hallado cortados y sarzenados en algunas ciudades de Andaluzia (fol. 237). 
28) 1728 , septiembre, 18 .

Real Provision en que va inserto Real Decreto de Su Magestad en que se Aumenta la Moneda de Plata, y oro, esto es, el Real de a ocho, que valia por nuebe Reales y medio, corra por diez, y el medio escudo por cinco Reales de plata, de a 16 quartos de Bellon cada uno: Y que el Doblon de a ocho escudos de oro valga 16 pesos: el Doblon de a quatro, por ocho, el Doblon Senzillo, por quatro, y el escudo, por dos (fol. 195).

\section{9)}

Registrado en el Libreo $3^{\circ}$ de Villetes. fol. 49. Para que los corregidores y demas ministros hagan las mas exactas diligenzias para la aberiguacion de los que han cortado o descantillado muchas piezas de a dos reales de plata u de los que las distribuyen (fol. 237).

30) 1728 , diciembre, 10.

Papel de su Excelencia de 10 de Deiziembre 1728 en que va integra Carta del Señor Fiscal del Consejo en que se manda nuevamente subsistan y se observen puntualmente las ordenes expedidas para que no corra la moneda cortada o serzenada ni tenga curso alguno (fol. 237).

\section{1) 1729 , enero, 9 .}

Registro $2^{\circ}$ de Acordes despues de regreso. Papel de su Excelencia de 9 de enero de 1729 en que se partezipa la Real resolucion de su Magestad a el comunicada por el señor Don Josep Patiño de que en la orden publicada el dia 16 de Dezembre 1728 sobre que no tuviessen curso las piezas de Reales de plata y de a dos Reales cortadas y zerzenadas, no veia comprehendida la moneda provinzial de los Reynos de Aragon Valencia, Mallorca y Cataluña (fol. 226).

32) 1731, julio, 7 .

Papel de Su Excelencia de 7 de julio en que va inserta Carta de la Real Junta de Comercio sobre las faltas que deveran descontarse los Doblones, remitieno a dicho fin una pesita, para que se formen las correspondientes; y para que se prohiba el que se den los doblones bajo las penas que previene (fol. 67).

\section{3) 1731, junio, 16.}

Papel de su Excelencia de 16 de Junio 1731 en que va inserta Carta de 9 del mismo de la Moneda de Madrid incluyendo junta las pesas vulgarmente llamadas dinerales de las monedas de oro, y plata afinadas y marcadas con las pesas de las faltas para que en su consequenzia passe la Audiencia a la execucion de lo mandado por su Magestad (fol. 66). 
34) 1732 , octubre, 4 .

Papel de su Excelencia de 4 de octubre 1732 en que prebiene a la Audiencia haversele por el señor Don Joseph Patiño comunicado la ResoIucion de S.M. en asumpto de la novedad susciptada por Miguel Pujol negociante de esa ciudad coputando el Real de a ocho senzillo de 4 pezetas por 128 quartos y no por 127 quartos y medios sobre cuyo pie declara devia pagar el importe de las letras dicho Miguel Pujol por ser conforme a la Practica que se observa sin contradizion al tiempo que las accepto y son quanto al valor del peso, en carga la puntual obsservanzia de la Pragmatica de año 1728 y demas publicadas en aumento de moneda (Acordadas 4. fol. 131).

\section{5) 1733, marzo, 21.}

Papel de Su Excelencia de 21 de marzo 1733 comunicando a la Audiencia la resolucion decraratoria (sic) de la Real Junta de Comercio, y de Moneda de Madrid a los capitulos 6 y 8 de agosto 1732 dadas y comunicadas a la congregacion collegio y Arte de Plateros de esta ciudad (fol. 132).

36) 1735 , noviembre, 7 .

Copia certificada de la Real Provision del Consejo de 7 de noviembre de 1735 sobre el valor de la Moneda que se fabrica en Indias, mandando que el real de a dos de los nuevos que se fabrican con el cuño, que expresa la provision, valiese 40 quartos de vellon /o/ calderilla, el real de plata 20; y diez el medio real de plata de la expresada nueva fabrica (fol. 146).

37) 1737 , mayo, 17.

Carta del Señor Governador del Consejo de 17 de mayo de 1737 en que se remite la Real Pragmatica sobre el aumento que su Magestad se servido dar a las Monedas de Plata (fol. 78).

38) 1737, agosto, 29.

Real Provision del Consejo de 29 de Agosto de 1737 comprehensiva del Real Decreto de su Magestad sobre el aumento de la moneda de Plata Provincial (fol, 82).

\section{«COMENTARIA»A LA TIPOLOGÍA MONETAL}

La pragmática del catálogo núm. 9 se refiere a la moneda acuñada durante el asedio de Barcelona por don Juan de Austria en 1652 con el escudo de la ciudad y Barcino Civitas obsessa cuyo documento trae Botet (Les Monedes catalanes III, 536-537). 
- Pragmática núm. 10. Se alude a la nueva moneda de cobre mandada fabricar en Barcelona, marca B, Zaragoza, marca Z, y Valencia marca murciélago, en anversos Philippus V D.G. Hispaniarum Rex y escudo corona o con castillo y león partidos y lises de la nueva dinastía cortado y en reverso Utrusque Virtute Protego y el año, con león rampante a derecha con cetro, corona y espada sobre ambos mundos por valor de IIII, II y I maravedí. Carlos III tendría los mismos valores, 4, 2 y 1 en los acuñados en Segovia, con su efigie y marca la puente en anverso Carolus III DG. Hisp(anirarum) Rex y el año en anverso y leones y castillos en cruz con las lises dentro de laurea anepígrafa (Heiss, I, lám. 57).

- Pragmática núm. 19. Siendo la base del oro el escudo y la más corriente pieza el doblón, se aplicó este nombre a los múltiplos, doblón de a cuatro y de doblón de a ocho, que serían éstos, bajo Carlos III, la media onza y la onza, respectivamente.

- Pragmática núm. 20. El peso escudo de plata era el real de a ocho, peso por la influencia que venía de Indias, de llamar así a aquel múltiplo. Pesos y medios pesos eran respectivamente los reales de a ocho y de a quatro que venían de los Reinos de Indias. Era la forma exacta de llamar a aquellas tierras del Hispaniarum et Indiarum Rex. (Véase Mateu y Llopis, Felipe. El título «Rex Indiarum» del Hispaniarum Rex en las monedas y en las medallas, «Historia, Instituciones, Documentos", núm. 7, Universidad de Sevilla 1981, 27 p).

- Pragmática núm. 32. La pesitase refiere a las que pueden verse como ponderal en Catálogo de los ponderales monetarios del Museo Arqueológico (1934) del citado autor.

\section{OBSERVACIONES PALEOGRÁFICAS Y DIPLOMÁTI- CAS DEL REGISTRO ÍNDICE DE ACORDADAS}

Diplomáticamente, los enunciados del documento definen la naturaleza del mismo creando una tipología propia de la compleja organización de las series archivísticas generadas por las funciones y competencias de la Real Audiencia, y que, en el caso de los registros borbónicos, son la continuación de los que la anterior cancillería venían a cumplir su cometido. Son compilaciones documentales con carácter neutro, donde se asientan, en el caso del volumen de Índice, a dos columnas, generalmente en forma de rúbrica o epígrafe en el margen izquierdo, y en forma de regesta completa en el derecho, el asunto tratado, con indicación del folio del registro corres- 
pondiente donde figura el documento completo. En el caso de la cancillería, anterior a los Borbones, el volumen de indices al final de cada número determinado de la serie, no existía de esta forma sistemática.

Los registros de la Audiencia Política (1714-1868), después de la estructura dada por Felipe V a partir del Decreto de Nueva Planta, se clasifican en: Actas Acordadas, Curiae, Diversorum, Edictos, Expedientes, Firmarum et Obligationum, Minutas, Nombramientos, Officialium, Privilegiorum, Certificados, Sententiarum, Ventas, Villetes, etc. Los Papeles de su Excelencia, conservados en pequeños legajos de documentos plegados en unidades varias que siguen el expediente, contienen las peticiones dirigidas al Capitán General por parte del Ayuntamiento o particulares, para su posterior resolucion.

Respecto a lo legislado sobre moneda, la fisonomía diplomática de los documentos está determinada por designaciones como Real Pragmática, Carta, Real Cédula, Real Provisión, Copia Autorizada del Real Decreto, Real Decreto, Carta autorizada del Real Decreto de su Magestad, Real Provisión, Papel de Su Excelencia, Real Provisión, Villetes, Libro de Villetes, creando una génesis documental con estructura propia.

La letra propia de la usual caligrafía del siglo XVIII presenta ductus destrogiro, y abreviaturas propias por síncopa con letras exponenciales.

\section{CONCLUSIONES}

La documentación analizada revela que sus disposiciones afectan a: a) el respeto por la forma de la moneda y su talla justa; b) la comprobación y verificación de su peso legítimo; c) evitar la falsificación de la moneda, la cercenación de la misma y pena en que incurren los que así lo hicieran; d) la regulación del patrón moneda con la vigilancia de los aumentos de valores y acuñación monetaria; e) la tipificación del Doblo, Real de a ocho, Medios Escudos, Dinerillos de Aragón que corrían en el Principado de Cataluña después de 1714; f) la ordenación de las casas de moneda en ambos mundos y el aumento de la moneda de plata según la disposición real de 1737 en el que finaliza este volumen de Índices de Acordadas; g) los ensayos de monedas y metales que regulan el Gremio de Plateros.

Ésta es una aportación más que incide en las fuentes documentales para el estudio de la Historia Monetaria, y en el caso de Carlos III la rica documentación de la Real Audiencia ofrece en sus Índices cartas archivísticas fundamentales.

Está en estudio el caligrafismo iconográfico de los Índices de Acordadas, de interesante contenido. 